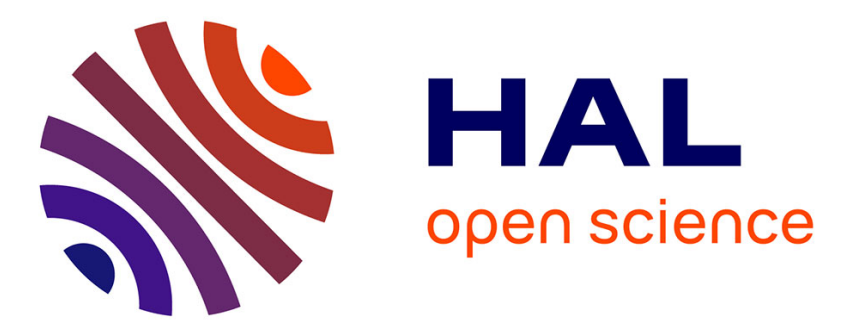

\title{
Quality of life in women with metastatic breast cancer during 9 months after randomization in the TEX trial (epirubicin and paclitaxel w/o capecitabine)
}

Helene Svensson, Zakaria Einbeigi, Hemming Johansson, Thomas Hatschek, Yvonne Brandberg

\section{To cite this version:}

Helene Svensson, Zakaria Einbeigi, Hemming Johansson, Thomas Hatschek, Yvonne Brandberg. Quality of life in women with metastatic breast cancer during 9 months after randomization in the TEX trial (epirubicin and paclitaxel w/o capecitabine). Breast Cancer Research and Treatment, 2010, 123 (3), pp.785-793. 10.1007/s10549-010-1084-8 . hal-00562276

\section{HAL Id: hal-00562276 https://hal.science/hal-00562276}

Submitted on 3 Feb 2011

HAL is a multi-disciplinary open access archive for the deposit and dissemination of scientific research documents, whether they are published or not. The documents may come from teaching and research institutions in France or abroad, or from public or private research centers.
L'archive ouverte pluridisciplinaire HAL, est destinée au dépôt et à la diffusion de documents scientifiques de niveau recherche, publiés ou non, émanant des établissements d'enseignement et de recherche français ou étrangers, des laboratoires publics ou privés. 


\title{
Quality of life in women with metastatic breast cancer during nine months after randomization in the TEX trial (epirubicin and paclitaxel w/o capecitabine)
}

\author{
Helene Svensson, RN, PhD student ${ }^{1,2}$ \\ Zakaria Einbeigi, $\mathrm{MD} \mathrm{PhD}^{2}$ \\ Hemming Johansson, Statistician ${ }^{3}$ \\ Thomas Hatschek, MD, $\mathrm{PhD}^{3}$ \\ Yvonne Brandberg, Psychologist, $\mathrm{PhD}^{4}$ \\ For the TEX-study group \\ ${ }^{1}$ Department of Oncology, Institute of Clinical Sciences \\ Sahlgrenska Academy at University of Gothenburg, Sweden \\ ${ }^{2}$ Department of Oncology, Sahlgrenska University Hospital, Division of Selected Clinical Specialities, Gothenburg, \\ Sweden. \\ ${ }^{3}$ Department of Oncology-Pathology, Radiumhemmet, Karolinska University Hospital, Stockholm, Sweden. \\ ${ }^{4}$ Department of Oncology-Pathology, Karolinska Institutet, Stockholm, Sweden
}

Keywords: Health-related quality of life, Metastatic breast cancer, Chemotherapy, EORTC QLQ-C30 \& EORTC QLQ-BR-23

Correspondence:

Helene Svensson

Department Of Oncology

Sahlgrenska University Hospital

SE 41345 Gothenburg

Sweden

e-mail: helene.svensson@gu.se

Phone: +46 313428678

Fax: + 4631823931 


\section{Introduction}

According to national guidelines, metastatic breast cancer in Sweden is treated with either endocrine therapy or chemotherapy, eventually in combination with biological treatment regimens. Women with metastatic disease have a relatively short expected survival time. Thus, the impact on health related quality of life (HRQoL) is an important factor to consider when making decisions about treatment at this stage of disease [1-5].

Between 2002 and 2007, a clinical trial known as the TEX trial comparing first line treatment regimens in patients with metastatic breast cancer was run by the Swedish Breast Cancer Group. As the TEX-trial was carried out in metastatic disease, HRQoL was included as a secondary endpoint. The aim of this paper is to present HRQoL data and to compare the effects of two treatment regimens on HRQoL at five assessment points during the nine months from random assignment to treatment and to examine any differences between the treatment groups at two of these points. The specific research questions were: (i) Were there differences between the two treatment groups two months after randomization? and (ii) Were there differences between the two groups nine months after randomization?

\section{Material and methods}

\section{$\underline{\text { Patients }}$}

Women over 18 years with documented locally advanced or distant metastatic breast cancer with measurable or evaluable lesions were accepted for inclusion in the TEX trial. The exclusion criteria were adjuvant therapy in the past year, previous use of any of the investigational drugs, cumulative doses of epirubicin exceeding $550 \mathrm{mg} / \mathrm{m}^{2}$ or doxorubicin exceeding $350 \mathrm{mg} / \mathrm{m}^{2}$, over expression of HER2, previous chemotherapy for metastatic disease, previous malignancy within five years, brain metastases, or any diseases preventing adequate study treatment.

A total of 287 patients from ten Swedish hospitals were randomized in the TEX trial between December 2002 and June 2007, 143 in the ET treatment arm and 144 in the TEX treatment arm. 


\section{$\underline{\text { Treatment regimens }}$}

ET group: epirubicin plus paclitaxel. Epirubicin $75 \mathrm{mg} / \mathrm{m}^{2}$ was given on day 1 as a 30 minute infusion followed by a 3 hour infusion with paclitaxel $175 \mathrm{mg} / \mathrm{m}^{2}$. The treatment was repeated every 3 weeks. Patients were offered second line treatment with oral capecitabine when the disease progressed.

TEX group: epirubicin plus paclitaxel plus capecitabine. Epirubicin $75 \mathrm{mg} / \mathrm{m}^{2}$ was given on day 1 as a 30 minute infusion followed by a 3 hour infusion with paclitaxel $155 \mathrm{mg} / \mathrm{m}^{2}$. Oral capecitabine $825 \mathrm{mg} / \mathrm{m}^{2}$ was given twice daily for 14 days. The treatment was repeated every 3 weeks.

All patients received premedication with intravenous betamethasone, intravenous ranitidine, and oral cetirizine before the start of treatment. After the first course, each of the drugs was stepwise dose-escalated or de-escalated depending on the severity of side effects reported by the patients. When the disease progressed, the patients were offered treatment according to local guidelines for second line treatment.

\section{$\underline{\text { Randomization }}$}

The randomization form was sent to the Clinical Trial Office (CTO), Clinical Trial Unit, Radiumhemmet, Karolinska University Hospital, Stockholm, Sweden, and faxed from there to the Oncologic Center, Sahlgrenska University Hospital, Gothenburg, Sweden for randomization. An answer was delivered within 24 hours. Randomization was performed using a permuted block technique. Stratification was made for the ten participating study centers.

\section{Points of assessment}

HRQoL was assessed at five points during nine months. The first point of assessment was after informed consent but before randomization, and the subsequent assessment points were two, four, six, and nine months after randomization. Two assessment points were of special interest: two months after randomization, when treatment had started and side effects were expected to be most prominent, and nine months after randomization, when the patients were considered to have adapted to the treatment or switched to other treatment. Assessments at four and six months were included to allow more detailed study of the effects on HRQoL of treatment over time. 


\section{$\underline{\text { Data collection procedure }}$}

Patients received the first questionnaire from the study nurses and were asked to complete it before being given information about the treatment to which they had been randomized. At the following assessment points, the questionnaires were sent by mail from the Clinical Trial Unit, Karolinska University Hospital together with an information letter and a return envelope. One reminder was sent if no reply was obtained within two weeks. Patients who had relapsed were still included in the HRQoL evaluation.

\section{$\underline{\text { Instruments }}$}

The European Organization for Research and Treatment of Cancer Quality of Life Questionnaire C30 (EORTC $Q L Q-C 30)$ is a HRQoL questionnaire developed by the EORTC Quality of Life Study Group to measure quality of life in cancer patients in clinical trials [6]. It consists of 30 items comprising five function scales: physical (PF), emotional (EF), social (SF), role (RF), and cognitive (CF); and three symptom scales: fatigue (FA), nausea/vomiting (NV), and pain (PA). A number of single items are also included: dyspnea (DY), insomnia (SL), appetite loss (AP), constipation (CO), diarrhea (DI), and financial difficulties (FI). The last two items assess global health and overall quality of life. Most items are responded to on a four point scale ranging from 1 (not at all) to 4 (very much). The two items assessing global health and overall quality of life are responded to in seven categories ranging from 1 (very poor) to 7 (excellent).

The EORTC QLQ Breast Cancer Module ( $Q L Q B R-23)$ is a breast cancer specific questionnaire developed for use among patients varying in disease stage and treatment modality [7]. It comprises 23 items divided into four functioning scales: body image (BRBI), sexual functioning (BRSEF), sexual satisfaction/enjoyment (BROSE), and future perspective (BRFU); and four symptom scales: systemic therapy side effects (BRST), breast symptoms (BRBS), arm symptoms (BRAS), and being upset by hair loss (BRHL). The questionnaire has been validated in an international study [7]. Completion of the questionnaire takes about 10-20 minutes. The items are responded to in the same four categories as most items in the EORTC QLQ-C30.

In the present study, three subscales from the EORTC-BR23 were of interest: BRBI, BRFU, and BRST. 


\section{$\underline{\text { Statistical methods }}$}

The main endpoint in the TEX study was time to progression while HRQoL was considered a secondary endpoint. It was estimated that with a sample size of 142 evaluable patients per treatment arm it would be possible to detect an increase in median progression-free survival from 6 months by 2.5 months with a power $(1-\beta)$ of $80 \%$ at an overall significance level $(\alpha)$ of $5 \%$.

All the single items in the EORTC QLQ-C30 and BR-23 were linearly transformed to functioning or symptom scales ranging from 0 to 100 according to the scoring manual [8]. A high score on the functional scales and global quality of life represents high level of functioning and quality of life. A high score on the symptom scales represents a high level of symptoms [6].

The expected mean value for each of the QLQ-C30 subscales was calculated using the age distribution in both groups combined together with age-specific mean reference scale scores from the Swedish population [9].

The effect of treatment on each of the scale scores at the time points of interest (two and nine months) was evaluated using linear regression models including both treatment and baseline values for the studied scale. Considering multiple testing, the results from the regression analysis are presented as mean differences together with $99 \%$ confidence intervals. Linear mixed-models were used to study treatment, time, and the treatment-time interaction (all treated as fixed effects) using all available longitudinal data.

In the interpretation of the QLQ-C30 and BR-23 scores, a difference of $\geq 5$ points on the 0 to 100 scale was considered clinically important. Differences of 5-9 points were considered small, those of 10-20 as moderate, and those $>20$ as large (10).

Due to multiple testing, the level of statistical significance was set to 0.01 to avoid type I errors. All analyses were 
performed according to the "intention to treat" principle.

\section{Results}

The number of patients included in the clinical trial, the number of patients excluded between each assessment point, and the number of respondents to the questionnaires at the five assessment points are presented in Table 2. Median time on treatment for the entire study population was 5.5 months, time to progression 11.9 months (not significant)

Of the 287 women with metastatic breast cancer randomized to the ET group ( $n=143$ ) or to the TEX group ( $\mathrm{n}=144)$, $252(88 \%)$ responded to the questionnaire at randomization and $163(70 \%)$ responded at all five points of assessment. The patients have responded to the questionnaire irrespective of whether they were still on the study treatment or went off for different reasons. eg. toxicity, good response or progressive disease. Patient characteristics are presented in Table 1.

\section{HRQoL at baseline}

Observed mean scale scores for the combined study group and expected scores on EORTC QLQ-C30 subscales and three subscales from EORTC-BR23 are presented in Figure 1. Statistically significant $(p<0.01)$ differences between the study groups were found at baseline for two of the subscales (global quality of life and physical functioning).

\section{HRQoL at the two-month assessment}

Mean scores and standard deviations (SD) for the EORTC QLQ-C30 and EORTC-BR23 subscales, two and nine months after randomization, divided by group, are presented in Table 3. There were no statistically significant differences between the TEX group and the ET group on any of the subscales two months after randomization. Small clinical differences in favor of the ET group were found for global quality of life, role functioning and social functioning. The ET group scored clinically lowers than the TEX group on fatigue, dyspnea, and diarrhea. However, a small clinical difference was found for insomnia, lower levels of problems, and this time in favor of the TEX group. No other clinical differences were found between the two groups at the two-month assessment regarding EORTC QLQ-C30. A small clinical difference was found for future perspectives, favoring the TEX group. 
HRQoL at the nine-month assessment

At the nine-month assessment, the TEX group scored statistically significantly higher than the ET group on global quality of life and physical functioning (Table 3). No other statistically significant differences were found for any of the subscales analyzed. In contrast to the findings at the two-month assessment, small clinical differences were found in favor of the TEX group for global quality of life, physical functioning, role functioning, emotional functioning, dyspnea, and insomnia.

There were no statistically significant or clinical differences between the TEX group and the ET group on any of the three EORTC-BR23 subscales nine months after randomization.

Analyses using all longitudinal data (linear mixed models) (Figure 2).

The strongest interactions between treatment and time in these models were found for global quality of life $(\mathrm{p}=0.003)$, role functioning $(0.005)$, and physical functioning $(\mathrm{p}=0.015)$, indicating that HRQoL scores differed between treatment groups over time. For emotional functioning, the interaction was not statistically significant $(\mathrm{p}=0.78)$. When the interaction terms in this model were dropped, the main effect of treatment was statistically significant $(\mathrm{p}=0.002)$ and the difference was estimated at 7.5 (1.2 to 13.8) in favor of TEX. This difference, however, was already present at baseline. There were no statistically significant interactions or main treatment effects on any of the three EORTC-BR23 subscales.

\section{Discussion}

In the present study, two regimens of first line chemotherapy in metastatic breast cancer were compared with respect to HRQoL at two selected time points: after two months, when treatment side effects were expected to be at worst, and after nine months, when the women were supposed to have adapted to the treatment or to have been offered other treatment due to toxicity or disease progression.

Several studies have been published regarding HRQoL among women treated with first line chemotherapy for metastatic breast cancer [5, 11-13]. Two of these studies showed a significantly better response rate and time to progression, but no significant differences in HRQoL were found between the two treatment regimens studied 
$[12,13]$.

Chemotherapy combinations with anthracyclines and taxanes have shown significant improvement in outcome, in terms of both time to progression and overall survival $[14,15]$. In addition, Jassem et al. found differences in HRQoL between women randomized to doxorubicin and paclitaxel (AT) versus fluorouracil, doxorubicin, and cyclofosphamid (FAC). Women in the FAC group scored higher on physical and sexual functioning and lower on pain, fatigue, insomnia, and diarrhea than those in the AT group. The AT group reported less nausea and vomiting [14]. Some of the published studies showed no differences in either HRQoL or overall survival $[5,16,17]$.

Bottomley et al. found no statistically significant differences between the AC and AT regimens in terms of either HRQoL or any of the following issues: progression-free survival, response rate, safety, or survival. HRQoL was impaired in both groups over time, in association with systemic therapy side effects, but there was no clear difference between the two regimens on any HRQoL scale, probably because the two regimens had the same clinical efficacy and similar toxicities [3].

In summary, almost all of the abovementioned studies showed little difference in HRQoL between different treatment groups of breast cancer patients receiving chemotherapy for metastatic disease. These findings are consistent with our results, where few differences were found between the treatment groups.

Comparisons of all scales at the two-month and nine-month assessment points were controlled for differences at randomization. However, systematic bias cannot be excluded. The fact that there were 11 patients with performance status ECOG 2 in the ET group compared to two in the TEX group at randomization could be one explanation. ECOG 2 status implies that the patient is ambulatory, capable of all self care though unable to carry out any work activities, and up and about for more than $50 \%$ of waking hours, but may have limited functioning in a number of areas. It could therefore be expected that patients with ECOG 2 would score lower on HRQoL than those with ECOG 0 to 1.

Small clinical differences were found in favor of the ET group at the two-month assessment, at which point treatment 
side effects could be expected. The TEX group received three different drugs, due to the addition of capecetabin to the drugs used in the ET group, and hence the increased burden of side effects was mirrored by the decrease in global quality of life. Diarrhea is one of the side effects of capecetabin, and a small clinical difference was found between the groups with respect to this symptom.

Emotional functioning improved in both groups from randomization to the two-month assessment. This finding is in agreement with previous studies showing that emotional problems decline after start of treatment $[3,18]$.

Both treatment groups reported decreased pain at the two-month and nine-month assessments. The frequency of bone metastases was equal between the treatment groups. We assume this result to be an effect of the treatment as previously described $[19,20]$.

At the nine-month assessment, the TEX group reported higher levels of global quality of life than the ET group. This difference could also reflect the influence of the differences in ECOG status found at randomization. It is, however, encouraging that the women in the TEX group seemed to have recovered from the decreased level of global quality of life found at the two-month assessment.

It is likely that for some patients, the time of responding to the HRQoL questionnaires coincided with radiographic evaluation of their tumor. There is a risk that patients who were informed by the physician that the treatment had had an effect may have reported fewer symptoms and better functioning than those who received negative information about the effect of the treatment. However, as the two groups did not significantly differ in terms of time to progression, this possible effect would not imply differences in HRQoL between the groups.

The present study has a number of strengths. It was conducted within a randomized clinical trial and all participants in the trial were offered inclusion in the HRQoL study. Compliance at baseline was $88 \%$, slightly higher than in other published data [3, 14]; Jassem et al. reported 77-81\% baseline compliance [14] and Bottomely 79\% [3]. Another strength was the use of standardized validated questionnaires. The procedure for data collection conducted by the Clinical Trial Unit ensured that questionnaires and reminders were sent at the time points decided upon. 
However, HRQoL evaluations in the setting where patients with treatment failure receive second or third line treatment have limitations. When comparing the effects, some of the patients may have changed to other treatments than they were randomized to. Therefore, it is actually also the effect of the current treatment that is observed.

Ideally, HRQoL should be presented in connection to the clinical study, where data on progression are presented. However, we choose to present our data in a separate paper in order to give a fuller description of the HRQoL study. Publications of the clinical results of this trial are under preparation. Our results could be used when informing patients about the choice of treatment.

In conclusion, the present study shows that, at the two-months assessment when side-effects of chemotherapy had recently appeared, patients treated with the TEX combination did far worse than those receiving ET. However, after nine months, when the patients had adapted to treatment, the group of patients treated with the TEX combination seemed to have a slightly better quality of life. For chemotherapy regimens with small differences in response, time to progression, and survival, as has been observed in the present trial, HRQoL data provide important additional information on the usefulness of a treatment. Our results can be used when informing the patients about the HRQoL consequences of the two regimens studied.

Acknowledgements:

This research was funded by the King Gustav V Jubilee Clinic Cancer Research Foundation, the Swedish Cancer Society, and the Swedish Breast Cancer Association (BRO).

Members of the TEX study group:

Thomas Hatschek (Coordinating Investigator), Yvonne Brandberg (QoL), John Carstensen (Statistics), Mårten Fernö (Translational research), Marianne Frostvik Stolt (Laboratory), Mats Hellström (CTO), Maarit Maliniemi (CTO), Helene Svensson (CTO), Gunnar Åström (Radiology), Jonas Bergh, Judith Bjöhle, Elisabet Lidbrink, Sam Rotstein, Birgitta Wallberg (Karolinska Univ. Hospital, Stockholm), Zakaria Einbeigi (Sahlgrenska Univ. Hospital, Gothenburg), Thomas Walz (Linköping Univ. Hospital), Martin Söderberg (Malmö Univ. Hospital), Niklas Loman, Per Malmström (Lund Univ. Hospital), Martin Malmberg (Helsingborg Gen. Hospital), Lena Carlsson (Sundsvall Gen. Hospital), Birgitta Lindh (Umeå Univ. Hospital), Marie Sundqvist (Kalmar Gen. Hospital), Lena Malmberg (Karlstad Gen. Hospital) 


\section{References}

1. Young T, De Haes J, Curran D (1999) Collecting quality of life data in EORTC clinical trials-what happens in practice? Guidelines for assessing quality of life in EORTC clinical trials (internal report). Brussels, EORTC

2. De Haes J , Curran D, Young T, et al.(1999) Quality of life evaluation in oncological clinical trials - the EORTC model. The EORTC Quality of Life Study Group. Psychooncology. May-Jun;8(3):260-3

3. Bottomely A, Biganzoli L, Cufer T, et al (2004) Randomized controlled trial investigated short-term healthrelated quality of life with doxorubicin and paclitaxel versus doxorubicin and cyclophosfamide as first-line chemotherapy in patients with metastatic breast cancer: European Organization for Research and Treatment of Cancer Breast Cancer Group, investigational drug branch for breast cancer and the new drug development group study. J Clin Oncol. 22(13):2576-2586

4. Efficace F, Biganzoli L, Piccart M , et al (2004) Baseline health-related quality-of-life data as prognostic factors in a phase III multicentre study of women with metastatic breast cancer. Eur J Cancer 40(7):1021-30

5. Cassier PA, Chabaud S, Trillet-Lenoir V, et al (2008) A phase III trial of doxorubicin and dosetaxel versus doxorubicin and paclitaxel in metastatic breast cancer: result of the Erasme 3 study. Breast Cancer Res Treat 109(2):343-350

6. Aaronson NK, Ahmedzai S, Bergman B, et al (1993) The European organization for research and treatment of cancer QLQ-C30: a quality-of-life instrument for use in international clinical trials in oncology. J Natl Cancer Inst 85(5):365-376

7. Sprangers MAD, Groenvold M, Arraras JI, et al (1996) The EORTC breast cancer-specific quality-of-life questionnaire module: first results from a three-country field study. J Clin Oncol 14: 2756-2768.

8. Fayers PM, Aaronson NK, Bjordal K, et al (2001) On behalf of the EORTC quality of life group EORTC QLQ-C30 scoring manual, $3^{\text {rd }}$ edn. EORTC, Brussels

9. Health-related Quality of Life Measured by the EORTC QLQ-C30. Reference Values From A Large Sample Of the Swedish Population. H Michelsson, C Bolund, B Nilssson, Y Brandberg. Acta Oncologica Vol. 39, No. 4, pp. 477-484, 2000.

10. Osoba D, Rodrigues G, Myles J, et al (1998) Interpreting the significance of changes in health-related quality-of-life scores. J Clin Oncol 16(1):139-144

11. Kramer JA, Curran D, Piccart M, et al (2000) Randomized trial of paclitaxel versus doxorubicin as first line chemotherapy for advanced breast cancer: quality of life evaluation using the EORTC QLQ-C30 and the Rotterdam symptom checklist. Eur J Cancer 36(12):1488-1497

12. Riccardi A, Tinelli C, Brugnatelli S, et al (2000) Doubling of the epirubicin dosage within the 5fluorouracil, epirubicin and cyclophosphamide regimen: A prospective randomizes multicentric study on antitumor effect and quality of life in advanced breast cancer. Int J Oncol 16(4):769-776

13. Hakamies-Blomqvist L, Luoma M, Sjöström J, et al (2000) Quality of life in patients with metastatic breast cancer receiving either docetaxel or sequential methotrexate and 5-fluorouracil. A multicentre randomised phase III trial by the Scandinavian breast group. Eur J Cancer 36(11):1411-7

14. Jassem J, Pienkowski T, Pluzanska A, et al (2001) Doxorubicin and paclitaxel versus fluorouracil, doxorubicin and cyclophosphamide as first-line therapy for women with metastatic breast cancer: final 
results of a randomized phase III multicenter trial. J Clin Oncol 19(6):1707-1715

15. Botenbal M, Creemers GJ, Braun HJ, et al (2005) Phase II to III study comparing doxorubicin and dosetaxel with fluorouracil, doxorubicin and cyclophosphamide as first line chemotherapy in patients with metastatic breast cancer: results of Dutch community setting trial for the clinical trial group of the comprehensive cancer centre. J Clin Oncol 23(28):17081-7088

16. Chan S, Friedrichs K, Noel D, et al (1999) Prospective randomized trial of docetaxel versus doxorubicin in patients with metastatic breast cancer. J Clin Oncol 17(8): 2341-2354

17. Norris B, Pritchard KI, James K, et al (2000) Phase III comparative study of Vinorelbine combined with doxorubicin versus doxorubicin alone in disseminated metastatic/recurrent breast cancer: National cancer institute of Canada clinical trials group study MA8 J Clin Oncol 18(12):2385-2394

18. Brandberg Y, Michelson H, Nilsson B, et al (2003) Quality of life in women with breast cancer during the first year after random assignment to adjuvant treatment with marrow-supported high-dose chemotherapy with cyclophosphamide, thiotepa and carboplatin or tailored therapy with fluorouracil, epirubicin and cyclophosphamide: Scandinavian Breast Group Study 9401. J Clin Oncol 21(19):3659-3664

19. Bang SM, Park SH, Kang HG et al (2005). Changes in quality of life during palliative chemotherapy for solid cancer. Support Care Cancer 13(7):515-521

20. Mayer EL, Burstein HJ (2007) Chemotherapy for metastatic breast cancer. Hematol Oncol Clin North am 21(2):257-272 


\section{Copyright Transfer Statement}

\section{을 Springer}

\section{BREAST CANCER RESEARCH AND TREATMENT}

The copyright to thils article is transeforred to Springor (roopectiva to owner if other then Springer and fo: U.S. government employees: to the extent trensterabio) effectivo ff and whon the artlob le accepted for publicestion. The copyrlght transfer covers the exclushe right to roproduce and distribute the article.

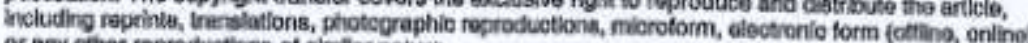
or any other raproductions of similer nature.

An author may sell-archlve sn author-ereated vorslan of hishar artlole on his/her own wobste and hisiher instilution's reposilory, includling hisher flnal versiont however hei she may not use the publisher's PDF version whlch is posted on www.springerilinkeom. Furthermore, the author may

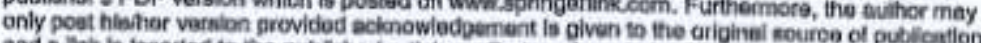

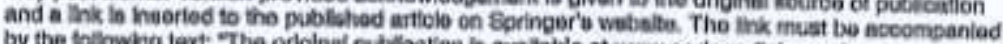
by the following text "The orlglnal pubilication is avaltabls et www.spitingorlink.com",

Please uso the approgrlato DOI for the articie fgo to the Liniking Options in the artiole, then to CpanURL and use the link with the DOi). Artiolos dlseminated vla www.sprngarlink oom are indoxed, abstracted, and roloronsed by many obstracting and intormetion sorvices, betlogriphib networks, autecription agondies, ibrary notworks, ond oonsortla.

The author warrants that ofis contribution is orginal and that he/she has full powor to maike this gront. The author slgna for and acoepts responsiblaty for robasaing thlis materlat on behalf of any
and atl co-authors.

\section{Finanelal Disclosure/Conflitet of Interest Statemant}

1, the undotatgnod nuthor, cerilfy that the authars of the Artiob have no sconmenciel assoctations

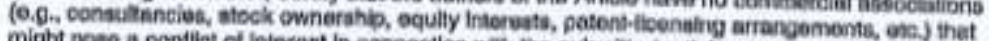
might poes a oontliet of interost in connection with the subinitied artble, oxoept as ditsclased an a sepurate attechinent. All funding sources supporting the work and all inettitional or corporate bifilietions of the authors are acknowlodged in a foolnote.

D Cheok here if a soparato attachmont is enclosed.

After nubmission of thia apreamunt algned by the curresponding wuthor cinanges of authorship or in the arrar of the atuathors Heted well not bo duceptad by Springot.

QUALTY OF LIFE IN WOMGN WITH METASTATIC BREAST OANCER Tlllo d anliole: DURING NINE MONTHS APTER RAJDOMIZATION IN THE TEOS TRLAL Authorla: HELEPRUBICIN AND PACLIAAE W/O CAPECITABINE) Aubrora sinnotuse: SVENSSck Date:

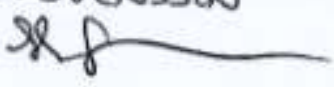

16 FEB 2010 